\title{
Generative Design of Articulated Rod of Radial Engine
}

\author{
H. VARIYAVWALA ${ }^{1}$, S.K. RAI ${ }^{2}$, H. KEAWMUANG ${ }^{3}$, L. SHATNAWI ${ }^{4}$ \\ ${ }^{1}$ University of Debrecen, Faculty of Engineering, Department of Mechanical Engineering, himanshuvariyavwala@gmail.com \\ 2University of Debrecen, Faculty of Engineering, Department of Mechanical Engineering, sawankrai@gmail.com \\ 3University of Debrecen, Faculty of Engineering, Department of Mechanical Engineering, harit.keawmuang@gmail.com \\ ${ }^{4}$ University of Debrecen, Faculty of Engineering, Department of Mechanical Engineering, shatnawi.s.laith@gmail.com
}

Abstract: The constant need for improvement drives humans to look for the best possible option in every field. Computer Aided Design (CAD) is no exception, to follow the best method of designing a product and finalizing it, researchers came up with an idea to generate multiple designs using fixed input values and finalizing the most appropriate one. The objective is achieved using an iterative design process based on algorithms by a specific software. Generative design introduces a new experience based on the Integration of machine dynamics in the manufacturing of objects and about experience. In this work generative design method was investigated on an articulated rod, one of the most important components of the rotary engine, to effectively improve the overall working performance of the engine and enhance its performance by decreasing its mass. Since fuel consumption by the machine can be greatly reduced by lowering the mass, so the goal is to minimize the weight of the rod while mechanical characteristics have to be within the acceptable values. Also, finite element analysis (FEA) was investigated on the part as to ensure the reliability of the rod before and after optimization.

Keywords: Generative Design, Radial Engine, 3D Modelling, Finite Element Analysis (FEA), Mesh Analysis.

\section{Introduction}

In today's demanding and developing world, recent design practices such as CAD may be inadequate or insufficient for different desires of consumers and validation of corporate ideologies. Hence, the courtesy of design has changed in the last few years [1]. That is when to do modification and development in the old design methods and tools, generative design came into the field. There are so many design parameters, limits, and requirements we have to take into consideration while designing such as design parameters, costs, applied loads, energy consumption, performance, product life etc. [2]. In traditional designing methods, in generative designing method, system generate the finished design autonomously based on the rules of creation and modification. There is no direct contact between the designer's product and the final output product because the system/design process will have to follow the codes and standards while designing [1]. There are lots of researchers who used generative design in their research and an impressive results. Francesco Buonamici regenerated a gripper arm by reducing the weight of the component considering some limits and also took care of the design parameters which was already given in the design problem [3]. Lin-Chien James Lee and Ming-Huang Lin modified the design features of the iPhone 4 case and printed it with a 3D printer [4]. D. Walton and H. Moztarzadeh used the topology optimization method and reduce the mass significantly in their research, Generative approaches can elaborate and propose number of alternative solutions, such as; to satisfy a set of imposed design constraints and to maximize a goal function passed to the algorithm. Dan Walton et al. 
have designed and developed the some methods like utilizing Electron-Beam-Melting method which includes topology-optimization. And based on the research he concluded that geometry could be conducted while topology optimization is used to decrease any requirement for supporting structures like processing time, cost of manufacturing [5]. In mechanical field, GD is not only Topology Optimization (TO), which provides plausible topologies can be optimized [3], and a unique method, however, it has different modules to reach to the optimal design using the Computer Aided Design software, based on the design objectives, some parameters need to be considered [2]. Erkan Gunpinar et al. have built a model based on mathematics to obtain the drag coefficient CD in their investigation and the goal was to estimate the shadow (right or left side of the body) of a sedan automotive. They were generating the initial designs using the generative design method, and after generating a specific number of the initial designs, they were divided on a certain design space. Every design were simulated using CFD software in order to obtain the parameters that the design performance is based on, such as the drag-coefficient CD and corresponding-drag-coefficients CDs. They utilized Artificial intelligence to form the required shapes, in addition to the fact that the math based model could expect CD factor for any design, thanks for a technique called principal-component-analysis PCA, in addition, to utilize the neural-network algorithms to obtain these values [9]. After that analysis, a math-based model was generated with an error the accepted range and a good reliability, they have managed to obtain 20 designs for automobiles their drag coefficient values were less than 0.3 [9]. Meisam Abdi et. al. focused on optimization of designing a car component using generative design methods, which are used to generate new designs by utilizing the topology optimized results, ISO surface of performance-criterion and generalized FEM [10]. Wu Yuanhang et. al. has been achieved new design for a face gear and its pinion by using a developed technique, which was based on the changing positions of points exist on the surface, and these changes leads to change of geometry[11]. The points that has been chosen to represent the geometry were built roughly initially. They achieved to their design by 2 steps; firstly, sampling the points that they chose by equal spaces between them based on the tooth shape and secondly, calculating the chosen points based on the mapping algorithm[11]. Gavacova J., Veres M., and Grznar M. proposed a generative design-based approach by which they said that shape of the car can be described by mathematical formulas which were gathered into a particular algorithm. The algorithm can be used to define design parameters and constraints, it can be used to control the whole design process [12]. They also invented general procedure of the automotive based generative design for engineers to apply this procedure to their own design to reduce designing time. A car's hood bonnet was used as an example by the researchers for a better understanding about generative design method in the paper [12]. Li H. and Lachmayer R. aimed to improve a generative design approach by gathered various design knowledge pieces in the past and presented them into a new generative design procedure. The objective of their work is to help engineers and designers to minimize designing time and to design parts effectively [13]. In this paper, they used the new generative design approach on a bicycle peddle crank as an example to test how effective the generative design is comparing to a common design approach [13]. The results shown that the time and cost of bicycle peddle development was greatly minimized, also complex geometries optimization were a lot easier to accessed [13]. Ersin Toptas aimed to introduce a new innovative design approach of mechanical parts which is different from a general way of designing [14]. In this particular article, bicycle neck was selected by the researcher to test the artificial intelligence-based software. He put the desire constraints and conditions such as 
forces, production volume, angles, and thickness. After that, the software presented 16 different designs depending on the parameters input. The results presented that a generative design by using artificial intelligence-based software greatly reduced designing time and can produce various alternative options for the designers [14]. R. Petrov et al. aimed to optimize the door hinge of the electro car by using a generative design approach. There were 2 hinges being considered, which are the upper and lower hinge of the electro car's door. The goal of this development was to reduce the hinges mass while mechanical characteristics have to be within acceptable ranges [15]. The results shown that by using the generative design procedure, there were the higher in accuracy of the results and automatic interpretation of analysis results. The masses of hinge were minimized by $30 \%$ and other requirements were satisfied [15]. In another interesting work by D. Huri and T. Mankovits, use of a Support Vector Machine (SVM) could be a gamechanger in prediction of the best shape for rubber products. By using 2-dimensional shape optimization they achieved training data for machine learning which is then used in support vector regression method to predict the optimum shape of the rubber bumper [16]. Force-Displacement curve under compression load is the most important technical parameter in design of rubber bumper, which can be accomplished by iterative design method. In this research they, Dávid Huri and Tamás Mankovits, used SVM model (Surrogate model) to adjust Stochastic Search Method parameters instead of orthodox Finite Element Model, since this method requires far less calculations in comparison of FEM this work turned out much more efficient in optimizing shape of rubber bumper [17].

\section{Generative Design (GD):}

Generative Design (GD) tools have become an interesting tool approach in any technological field to overcome design problems. It helps the designers to find the right and most reliable solution by using design software such as Solid Edge. The main advantage of GD is its low time to reach to a reliable solution and its wide range of options and adjustability [6].

According to Kristina Shea; the generative design systems are being developed to develop new design processes by using current computational and manufacturing technologies which can generate spatially novel yet effective and buildable designs." [8]

\section{Properties of generative systems:}

The capacity to create complexity distant more noteworthy than the given totals.

The complicated and entangled relationship between the organism and its surroundings.

The feature to preserve and restore itself.

The capacity to build new systems, practices, results, or connections.

Application of Generative Design: Generative design can reduce the weight of the object, can improve the performance, part consolidation, reduce production time, can provide various design problems etc. It generates the product in a way that it can withstand against the load requirement given by designers and give the best optimal solutions by using the GD features of the CAD software. 


\section{Material and method}

\subsection{Assembly of Radial Engine}

The objective of this work is to redesign the articulated rod from the radial engine by using generative method. A reciprocating type internal combustion engine is known as a radial engine. Prior to the invention of gas turbine engines, the radial configuration was widely used for aircraft engines. Since the axes of the cylinders are coplanar, connecting rods cannot always be directly linked to the crankshaft, so the pistons are connected to the crankshaft by a master-and-articulating-rod assembly. The model of the radial engine that was produced using solid edge software can be observed in the Figure 1 and the details of individual parts are given in Table 1.

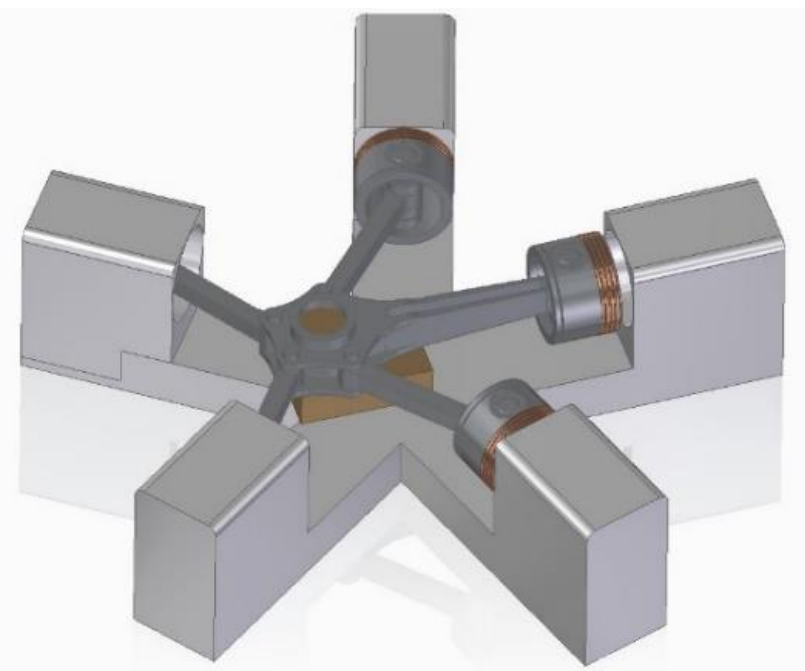

Figure 1: Assembly Design

\begin{tabular}{|c|c|c|}
\hline Name & Material & Weight \\
\hline Master rod bearing & Iron & $0.021 \mathrm{~kg}$ \\
\hline Rod Bush & Iron & $0.011 \mathrm{~kg}$ \\
\hline Piston & Steel 4340 & $1.406 \mathrm{~kg}$ \\
\hline Piston ring & Iron & $0.023 \mathrm{~kg}$ \\
\hline Piston Pin & Steel 4340 & $0.179 \mathrm{~kg}$ \\
\hline Piston Pin Plug & Steel 4340 & $0.017 \mathrm{~kg}$ \\
\hline Master rod & Steel 4340 & $2.204 \mathrm{~kg}$ \\
\hline Link Pin & Steel 4340 & $0.036 \mathrm{~kg}$ \\
\hline Articulated Rod & Steel 4340 & $0.615 \mathrm{~kg}$ \\
\hline
\end{tabular}

Table 1 : Assembly components details

\subsection{Articulated Rod}

The part that is focused for the design optimization is Articulated Rod. The model of Articulated Rod can be seen in the Figure 2. As mentioned earlier, the material of this part is Steel 4340, and its properties can be seen in Table 2 . 


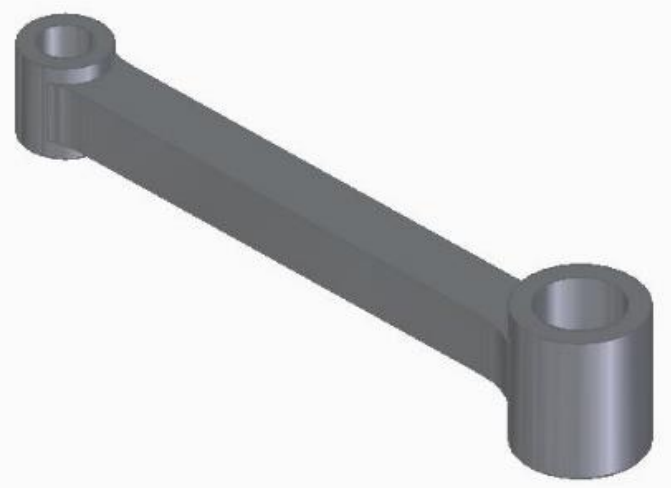

Figure 2: Articulated rod model

\begin{tabular}{|c|c|c|c|c|c|}
\hline Density & Modulus of elsticity & $\begin{array}{c}\text { Elongation } \\
\%\end{array}$ & $\begin{array}{c}\text { Poisson's } \\
\text { ratio }\end{array}$ & Yield stress & $\begin{array}{c}\text { Ultimate } \\
\text { stress }\end{array}$ \\
\hline $7850.000 \mathrm{~kg} / \mathrm{m}^{3}$ & $200000.000 \mathrm{MegaPa}$ & 22.000 & 0.285 & $470.000 \mathrm{MPa}$ & $745.000 \mathrm{MPa}$ \\
\hline \multicolumn{6}{|c|}{ Table 2: Steel 4340 properties }
\end{tabular}

\subsection{Applied force calculation:}

In this work, the applied force on the model is the force that is acting on the connecting rod in the engine. The force that is acted on the connecting rod is involved with 3 other forces, which are force on piston due to gas pressure, force that is caused by inertia of reciprocating mass and connecting rod, and force due to friction of piston and of piston ring. The calculation method is obtained from [16]. The relevant parameters can be observed in the Table 3 .

\begin{tabular}{|l|c|}
\hline Parameters & Value \\
\hline Bore diameter $(\mathrm{d})$ & $0.035 \mathrm{~m}$ \\
\hline Explosion Pressure $\left(\mathrm{p}_{\mathrm{e}}\right)$ & $120 \mathrm{bar}$ \\
\hline Mass $(\mathrm{M})[1 / 3$ of Connecting Rod + Piston + Piston Ring + Piston Pin] & $1.565 \mathrm{~kg}$ \\
\hline Angular Speed $(\mathrm{w})$ & $420 \mathrm{rad} / \mathrm{s}$ \\
\hline Crank Radius $(\mathrm{r})$ & $0.0477 \mathrm{~m}$ \\
\hline Angle between Crank shaft and Piston axis $(\theta)$ & $0^{\circ}$ \\
\hline Length of Connecting Rod $(\mathrm{l})$ & $0.178 \mathrm{~m}$ \\
\hline Angle between Connecting Rod and Piston axis $(\beta)$ & $0^{\circ}$ \\
\hline
\end{tabular}

Table 3: Calculation parameters

Force on piston from gas pressure $\left(\mathrm{F}_{\mathrm{a}}\right)$ can be calculated using the formulae below:

$$
F_{a}=\frac{\pi \mathrm{d}^{2} p_{e}}{4}
$$

From (1), we then obtain $\mathrm{F}_{\mathrm{a}}=11545.35 \mathrm{~N}$ 
Force that is caused by inertia of reciprocating mass and connecting $\operatorname{rod}\left(\mathrm{F}_{\mathrm{i}}\right)$ can be found by the following equation:

$$
F_{i}=M w^{2} r\left(\cos \theta+\frac{r * \cos \theta}{l}\right)
$$

Hence, from (2), $\mathrm{F}_{\mathrm{i}}=16614.04 \mathrm{~N}$

Force due to friction of piston and of piston ring $\left(\mathrm{F}_{\mathrm{f}}\right)$

From the research paper [7], $\mathrm{F}_{\mathrm{f}}=4000 \mathrm{~N}$

Force acting on piston $\left(\mathrm{F}_{\mathrm{p}}\right)$ is equal to three forces combined as follows:

$F_{p}=F_{a}+F_{i}+F_{f}=24159.39 N$

Force acting on connecting rod (F) can be known by the following equation.

$$
F=\left(\frac{F_{p}}{\cos \beta}\right)
$$

From (3), $\mathrm{F}=24159.39 \sim 25000 \mathrm{~N}$

\subsection{Method}

There are three main parts of the methodology, which are finite element analysis, generative design, and conventional redesigning shape of the model. Solid Edge was used to create the part model to conduct the finite element analysis, also it was used to do generative design and redesign of the component as well. First, the articulated rod, which is the focused part for improvement, was created. Then, the boundary conditions are applied to the model. The fix constraint was applied to the smaller circular ring. The force of $25000 \mathrm{~N}$ was given to the inner surface of the bigger cylinder. The boundary conditions of articulated rod model can be seen in the Figure 3 (left). After that, in order to observe the stress and displacement distribution in the model, finite element analysis was run. Also, mesh analysis was conducted to observe the change in the maximum stress, maximum displacement, and elapse time of the different subjective mesh size in order to select the most reasonable mesh size for the finite element analysis. In the mesh analysis, 10 different mesh sizes were applied to the model. Figure 3 (right) also shows the preserved region of the rod which will not undergo any changes during generative design so that the connecting parts doesn't need any changes after the generative design results are obtained. Next, the generative design of the part was started. The goal is to reduce the mass of the rod while the stress and displacement is within the acceptable range. The bigger and smaller cylinder were selected to be a preserved region, which will not change in shape after the new design is finished so that compatibility with existing parts remains unchanged. The chosen safety factor is 1.4 . The boundary conditions of generative design can be observed in the generative design was run with different chosen mass reduction from $10-50 \%$ of the rod's original mass to observe the various shape of the design. Finally, the conventional redesign was conducted to redesign the genitive designs shape to be manufacturable in the regular process. 

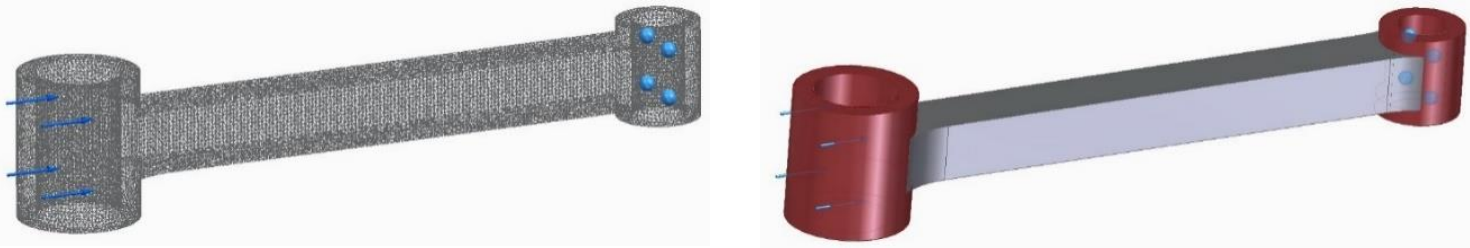

Figure 3: Mesh model along with boundary conditions (left) \& Preserved region for Generative design

\subsection{Results and discussions}

First of all, the different mesh sizes were applied to observe the maximum stress, maximum displacement, and solving time of the part. The results are illustrated in Table 4; Figure 4 represents the plot between mesh size versus maximum stress and mesh size versus maximum displacement.

\begin{tabular}{|c|c|c|c|c|}
\hline $\begin{array}{c}\text { Subjective mesh } \\
\text { size }(\mathbf{m m})\end{array}$ & $\begin{array}{c}\text { Meshing } \\
\text { time }(\mathbf{s})\end{array}$ & $\begin{array}{c}\text { Solving time } \\
(\mathbf{s})\end{array}$ & $\begin{array}{c}\text { Maximum stress } \\
\mathbf{( M P a})\end{array}$ & $\begin{array}{c}\text { Maximum } \\
\text { displacement }(\mathbf{m m})\end{array}$ \\
\hline 10.99 & 2 & 4 & 140 & 0.0843 \\
\hline 8.24 & 2 & 5 & 173 & 0.0869 \\
\hline 5.49 & 2 & 3 & 209 & 0.0888 \\
\hline 4.94 & 2 & 6 & 239 & 0.089 \\
\hline 4.39 & 2 & 5 & 231 & 0.0892 \\
\hline 3.84 & 2 & 6 & 231 & 0.0892 \\
\hline 3.3 & 3 & 10 & 226 & 0.0897 \\
\hline 2.75 & 7 & 14 & 229 & 0.0898 \\
\hline 1.92 & 14 & 50 & 241 & 0.09 \\
\hline 1.1 & 124 & 258 & 311 & 0.0902 \\
\hline
\end{tabular}

Table 4: Mesh analysis results

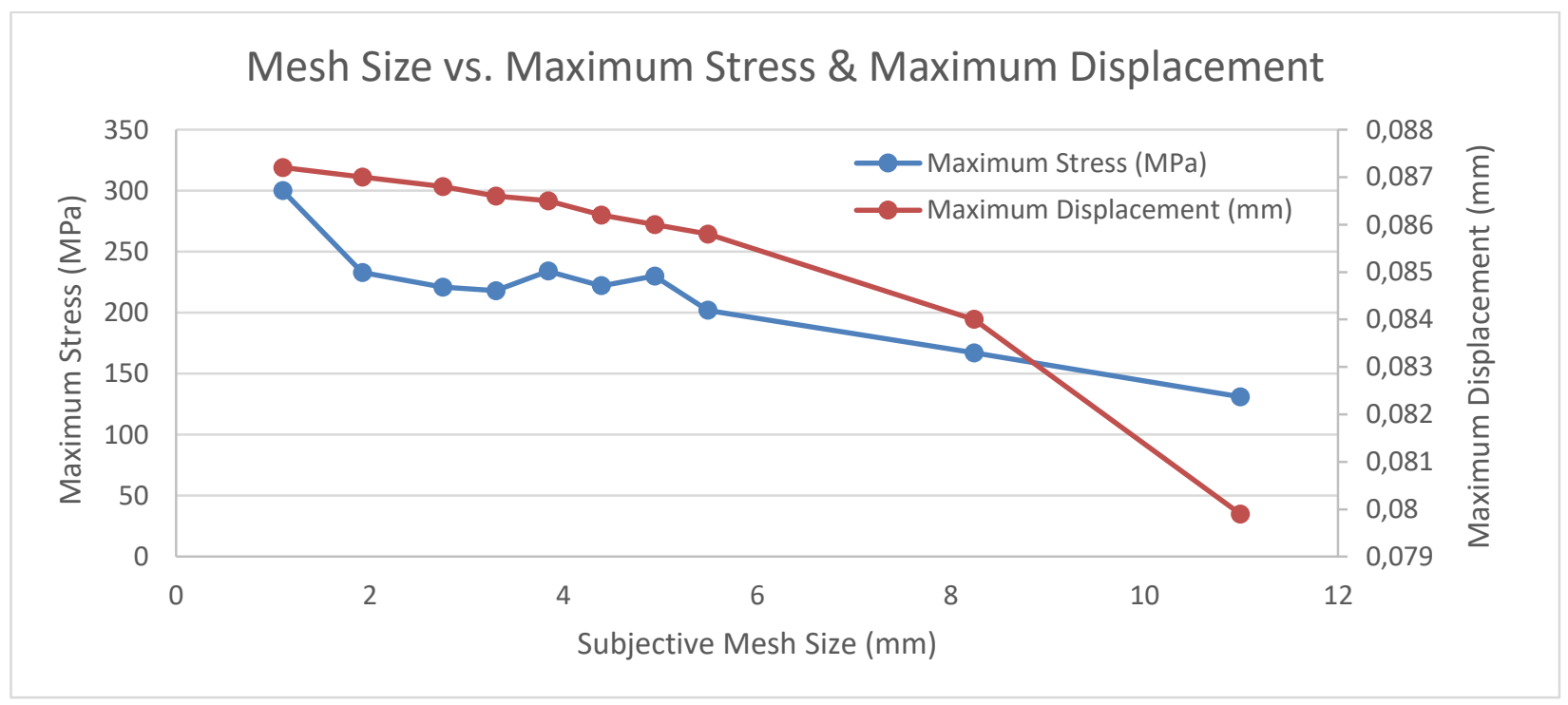

Figure 4: Mesh size vs Maximum Stress and Maximum Displacement

After analysing mess sensitivity it is concluded that the $1.10 \mathrm{~mm}$ of mesh size is most suitable one for our purpose because the results of stress and displacement are really good and the elapse time is not 
much higher. Figure 5 provides the FEA results, which show the stress and displacement distribution of the model.
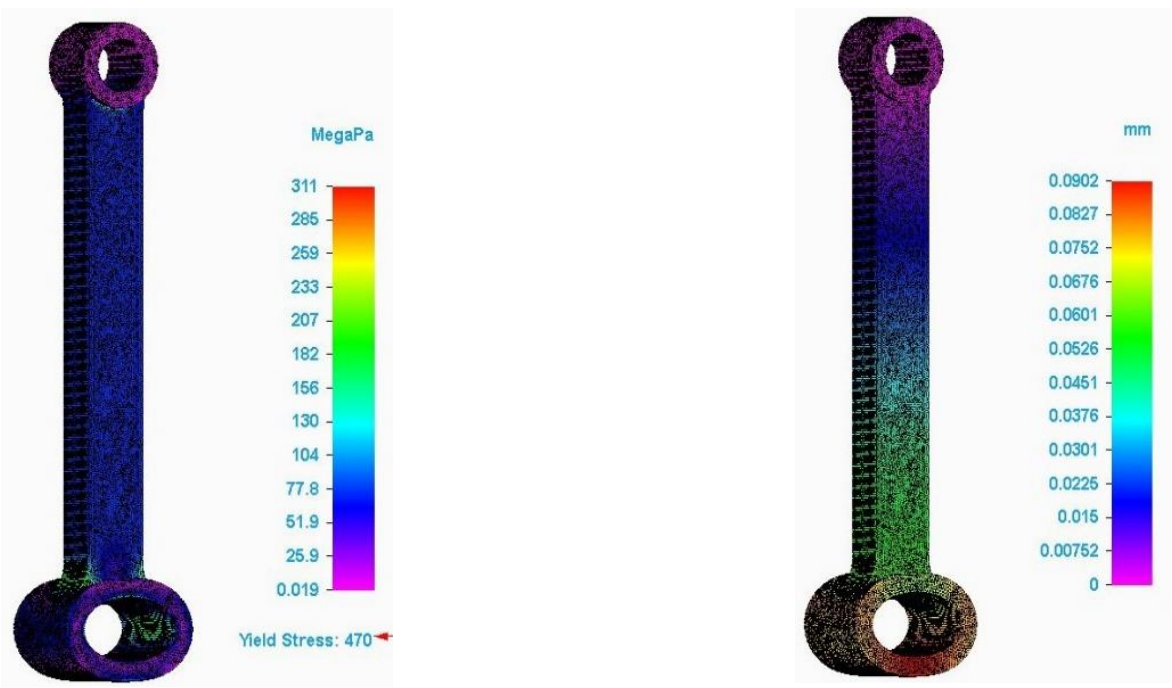

Figure 5: Stress distribution (left) \& Displacement distribution (right)

Once required mesh size has been finalised then generative designs can be obtained by varying different parameters, generative design of Articulated Rod of Radial Engine is created using Solid Edge CAD software. The designs are obtained in the various shapes, depending upon the constraints provided such as mass reduction percentage, elapse time and quality of the generated design. Mass reduction of the rod is observed within the range of $10-50 \%$ minimization of the original mass. The execution time varied from 20-30 minutes. Furthermore, factor of safety has been fixed as 1.4, considering the dynamic load of the rod. Figure 6 (a) and (b) shows the different designs obtained after the process along with the processing time and resultant weight of the rod.

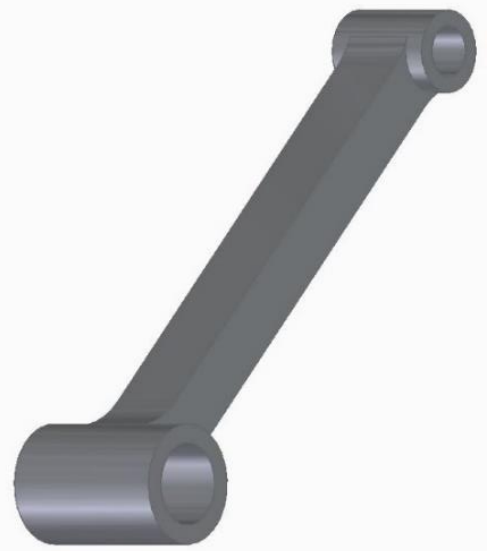

Original Mass $=0.615 \mathrm{~kg}$

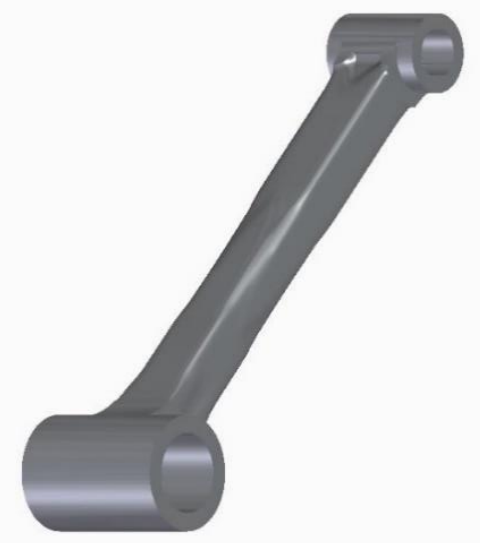

Reduction $=10 \%$

Run time $=20 \mathrm{~min}$ Mass $=0.553 \mathrm{~kg}$

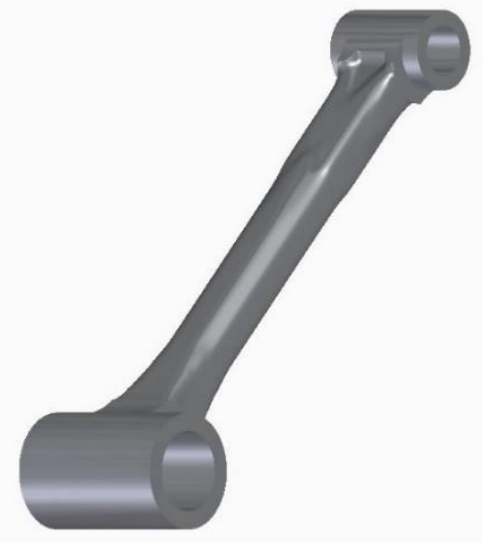

Reduction $=20 \%$

Run time $=20 \mathrm{~min}$ Mass $=0.492 \mathrm{~kg}$

Figure 6(a): Generative designs of Articulated Rod of Radial Engine 


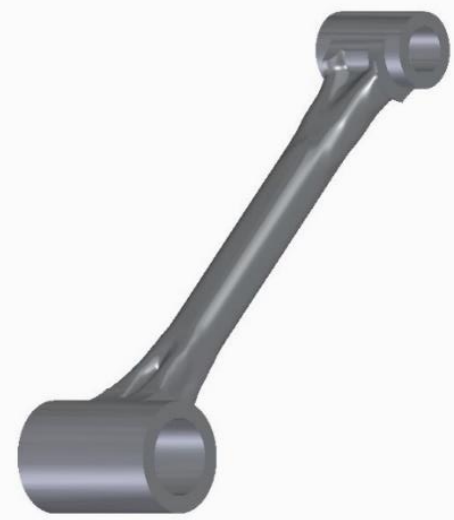

Reduction $=30 \%$

Run time $=30 \mathrm{~min}$ Mass $=0.430 \mathrm{~kg}$

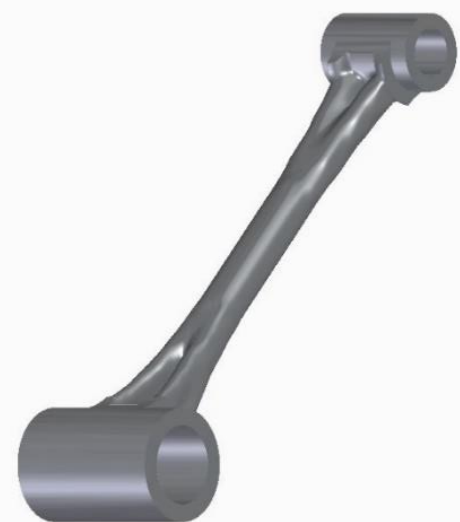

Reduction $=40 \%$

Run time $=30 \mathrm{~min}$

Mass $=0.369 \mathrm{~kg}$

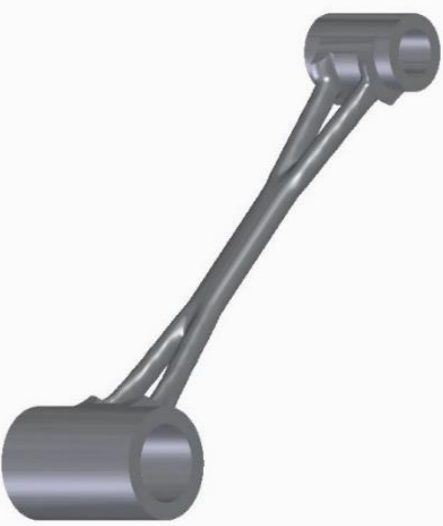

Reduction $=50 \%$

Run time $=30 \mathrm{~min}$

Mass $=0.3075 \mathrm{~kg}$

Figure 6(b): Generative designs of Articulated Rod of Radial Engine

Next step is conventional or practically possible redesigning of our product inspired by generative design results. We redesigned three different types of models in a way that it can be produce by conventional methods or CAM (Computer Aided Manufacturing). Thereafter, FEA is performed once again to check the feasibility of the redesigned models, results along with model designs can is shown in Figure 7-9. Once all completed, the design will be subjected to practical load testing to cross-check the real life feasibility of the models.

Model 1: Mass reduction of 23.6\%; New mass $=0.470 \mathrm{~kg}$

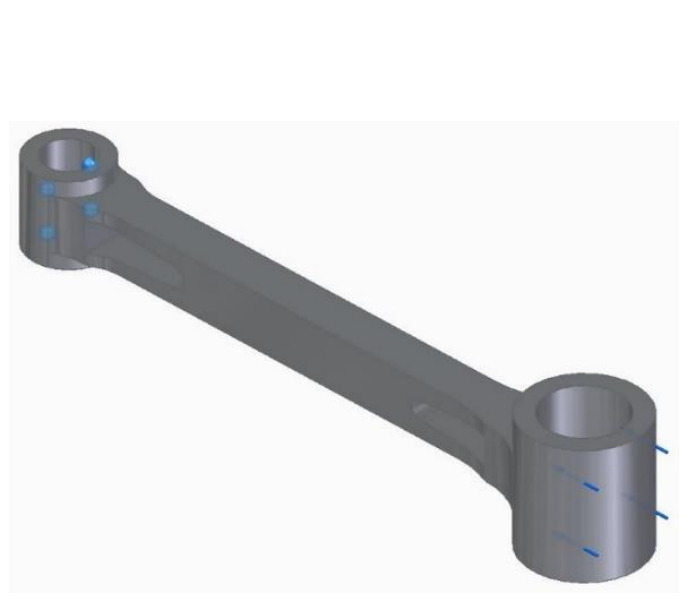

Isometric view

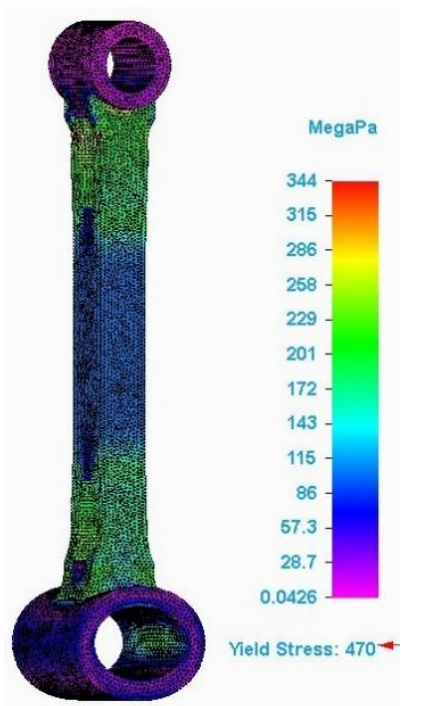

Stress distribution by

Von Mises stress

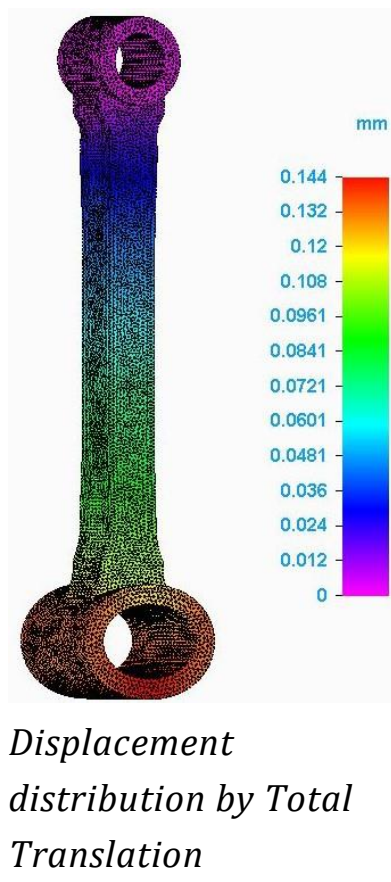

Translation

Figure 7: First Re-designed model with FEA results 
Model 2: Mass reduction of 30.9\%; New mass $=0.425 \mathrm{~kg}$

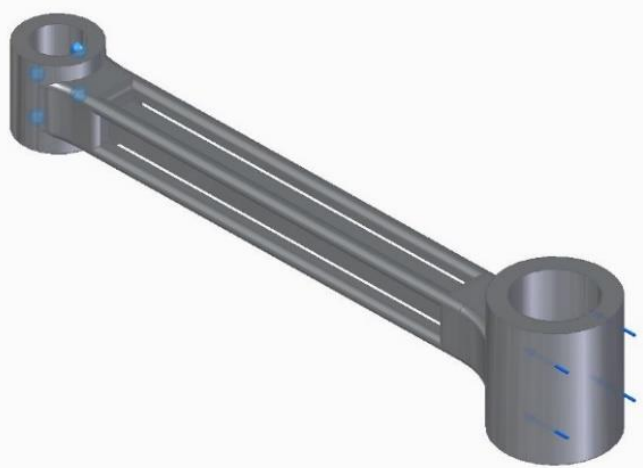

Isometric view

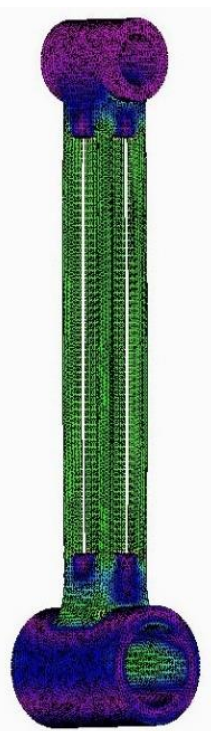

Stress distribution by Von Mises stress

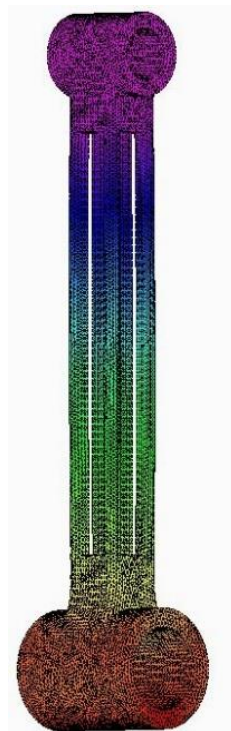

Displacement distribution by Total Translation

Figure 8: Second Re-designed model with FEA results

Model 3: Mass reduction of 36.1\%; New mass $=0.393 \mathrm{~kg}$

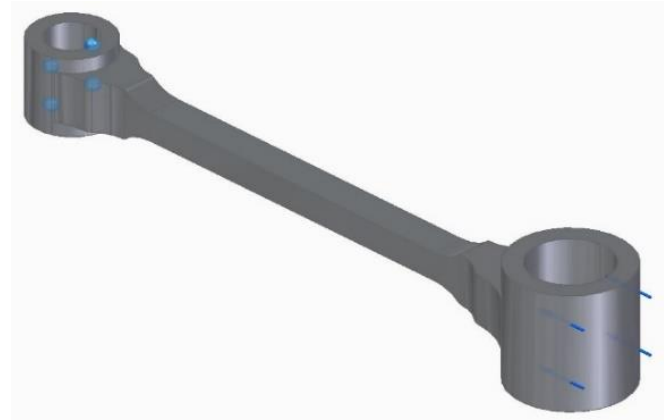

Isometric view
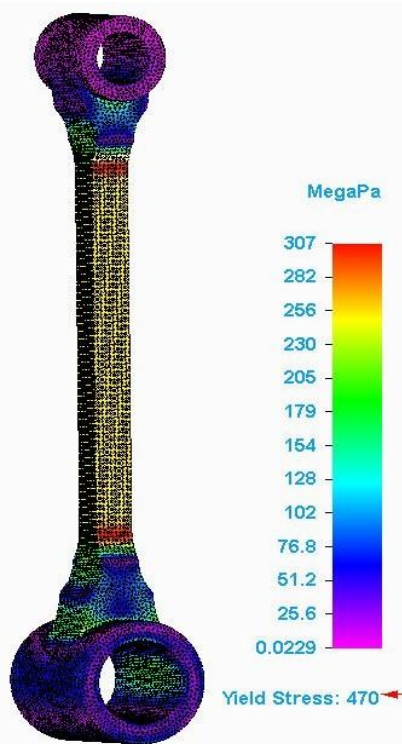

Stress distribution by Von Mises stress
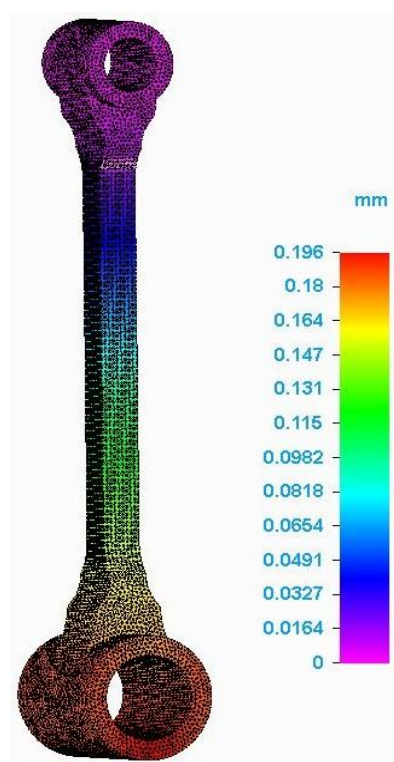

Displacement distribution by Total Translation

Figure 9: Third Re-designed model with FEA results 


\section{Conclusion}

After this investigation we can conclude that the generative design has a significant role in the industry in general and the machine design especially, in this investigation we have designed an articulated rod of a rotary engine based on a realistic dimensions and boudary conditions, the CAD model has been built using Solid Edge software, and the FEA has been done on the same software as well, in order to introduce it to the generative design part which is the main aim of this analysis.

The aim of the design has been achieved by reaching to a final design which can perform at optimum level and weighs less as compared to its counterparts. Though, the mass reduction has reached to $38 \%$, in some of the redesigned models, of the original mass, but failed under the loading conditions. Hence, it was omitted from the scope of the work and the maximum reduction achieved limeted to $36.1 \%$ (model 3). All designs are made taking factor of safety into consideration which was fixed for whole work i.e. 1.4. The material of the focused part is selected to be Steel 4340 which is an alloy of NickelChromium-Molybdenum known for its high toughness, wear resistance and quality to achieve high strenghts in heat-treated conditions. The maximum Von Mises stress in this FEA reached to $344 \mathrm{MPa}$ which is well within the yeild stress limit of the material (i.e. $470 \mathrm{MPa}$ ) and satisfies the factor of safety that was taken into consideration. In nutshell, the work produced satisfactory results and is ready to be tested in real life conditions before being used in the engines.

\section{References}

[1] “Jon McCornmack, Alan Dorin, and Troy Innocent, (2004) 'Generative Design: a paradigm for design research' in Redmond, J. et. al. (eds) Proceedings of Futureground, Design Research Society, Melbourne.Author, Title of the book or paper, Publisher, 34-56."

[2] "S. Bagassi, F. Lucchi, F. De Crescenzio, F. Persiani , Industrial Engineering Department, University of Bologna, ICAS 2016."

[3] "Francesco Buonamici, Monica Carfagni, Rocco Furferi1, Yary Volpe and Lapo Governi, Department of Industrial Engineering of Florence, Francesco Buonamici, https://doi.org/10.14733/cadaps.2021.144-155, Available from May-2020."

[4] "Lin-Chien James Lee, Ming-Huang Lin, National Chiao Tung University, Institute of Applied Arts, Taiwan, A. Marcus (Ed.): DUXU 2014, Part I, LNCS 8517, pp. 296-307, 2014. @ Springer International Publishing Switzerland 2014."

[5] D. Walton and H. Moztarzadeh, "Design and Development of an Additive Manufactured Component by Topology Optimisation," Procedia CIRP, vol. 60, pp. 205-210, 2017, doi: 10.1016/j.procir.2017.03.027.

[6] "https://archistar.ai/blog/the-generative-design-process-the-seven-key-stages-that-you-needto-know-about/."

[7] P. Singh, D. Pramanik, and R.V. Singh,"Fatigue and Structural Analysis of Connecting Rod's Material Due to (C.I) Using FEA,” IJAET, Vol. 4, Issue 4, pp. 245-253, 2015.

[8] K. Shea, R. Aish, and M. Gourtovaia, "Towards integrated performance-driven generative design tools," in Automation in Construction, 2005, vol. 14, no. 2 SPEC. ISS., pp. 253-264, doi: 10.1016/j.autcon.2004.07.002. 
[9] E. Gunpinar, U. C. Coskun, M. Ozsipahi, and S. Gunpinar, "A Generative Design and Drag Coefficient Prediction System for Sedan Car Side Silhouettes based on Computational Fluid Dynamics," CAD Comput. Aided Des., vol. 111, pp. 65-79, 2019, doi: 10.1016/j.cad.2019.02.003.

[10] M. Abdi, I. Ashcroft, and R. D. Wildman, "Design optimisation for an additively manufactured automotive component," Int. J. Powertrains, vol. 7, no. 1-3, pp. 142-161, 2018, doi: 10.1504/IJPT.2018.090371.

[11] Y. Wu, Y. Zhou, Z. Zhou, J. Tang, and H. Ouyang, "An advanced CAD/CAE integration method for the generative design of face gears," Adv. Eng. Softw., vol. 126, no. October, pp. 90-99, 2018, doi: 10.1016/j.advengsoft.2018.09.009.

[12] “A. T. Corviniensis and E. T. Vii, 'Computer Aided Generative Design,' no. April, pp. 18-22, 2014."

[13] H. Li and R. Lachmayer, "Generative Design Approach for Modeling Creative Designs," IOP Conf. Ser. Mater. Sci. Eng., vol. 408, no. 1, 2018, doi: 10.1088/1757-899X/408/1/012035.

[14] E. Toptas, "Innovative approach to the design of mechanical parts," J. Mechatronics Artif. Intell. Eng., vol. 1, no. 1, pp. 14-20, 2020, doi: 10.21595/jmai.2020.21473.

[15] R. Petrov, P. Cvetkov, A. Maksimov, and O. Klyavin, "On the problem of optimizing the door hinge of electro car by generative design methods," Int. J. Mech., vol. 14, no. July, pp. 119-124, 2020, doi: 10.46300/9104.2020.14.15.

[16] D Huri, T Mankovits, “Automotive Rubber Part Design using Machine Learning," IOP Conference Series: Materials Science and Engineering 659 pp. 1-6. Paper: 012022, 6 p. (2019).

[17] Dávid Huri, Tamás Mankovits "Parameter Selection of Local Search Algorithm for Design Optimization of Automotive Rubber Bumper," APPLIED SCIENCES-BASEL 10: 10 pp. 1-16. Paper: 3584, 16 p. (2020). 